\title{
Urinary Tract Infection by Trichomonas vaginalis in a Newborn Baby
}

\author{
J. M. LITTLEWOOD and H. G. KOHLER \\ From the University Department of Paediatrics and Child Health, and Department of Pathology, \\ the Maternity Hospital, Leeds
}

Trichomonas vaginalis (Donné) is a flagellate protozoon, commonly found in this country and considered to be a cause of purulent vaginal discharge. It is a common finding in pregnant women attending antenatal clinics. Sexual intercourse is believed to be the principal, but not exclusive, mode of infection, the male partner usually remaining free of symptoms. Infection by Trichomonas vaginalis in newborn infants is uncommon in this country, and when it does occur, the clinical form is usually that of a vaginitis (Crowther, 1962).

This article describes a case of urinary tract infection with Trichomonas vaginalis in a premature baby in whom there was no clinical evidence of vaginitis.

\section{Methods}

Specimens of urine were collected in clean 'sterilon' plastic bags, applied to the vulva after thorough cleansing of perineum and external genitalia with sterile water. White cells in uncentrifuged urine were counted in a Fuchs-Rosenthal chamber. In addition, $10 \mathrm{ml}$. of the same specimen were centrifuged for 10 minutes at 2800 to 3000 revolutions per minute. The supernatant fluid was discarded except for about $0.5 \mathrm{ml}$. in which the deposit was resuspended. Wet cover-slip preparations were examined immediately and the number of white cells per high power field estimated. Red blood cells, epithelial cells, micro-organisms, and other normal and abnormal structures were also noted. Cultures of the deposit were made on blood agar, with direct sensitivity tests applied, and also on McConkey's medium.

Vaginal swabs were examined microscopically for Trichomonas vaginalis by the wet film method which permits observation of the characteristic motility of these protozoa.

\section{Case Report}

Baby W., a female infant weighing at birth $1447 \mathrm{~g}$. ( $3 \mathrm{lb} .3 \mathrm{oz}$.) and $38 \mathrm{~cm}$. (15 in.) long was born after an

Received March 7, 1966. uneventful pregnancy of some 28 weeks' duration. The reason for the premature onset of labour was unknown. Delivery was normal and by the vertex.

The baby's condition at birth was satisfactory apart from mild respiratory distress during the first 6 hours of life. Although extremely premature, the infant looked healthy, and there were no detectable abnormalities of the abdomen or external genitalia. There was mild generalized oedema consistent with the gestational age. Two small haemangiomata first appeared in the second week, one on the abdominal wall and the other on the left thigh. For the first nine days progress was normal; the temperature was slightly unstable, in keeping with the infant's immaturity. She was nursed in an incubator and given expressed breast milk by gavage. There was a moderate degree of jaundice.

At the age of 10 days the weight was $1107 \mathrm{~g}$. $(2 \mathrm{lb} .7 \mathrm{oz}$.) and she was thought to be vaguely off colour by the nurse, but thorough physical examination and urine microscopy did not reveal any abnormality. On the following day the general condition was satisfactory and progress during the subsequent 8 days was uneventful.

On the 19th day there was considerable distension of the abdomen and the veins of the abdominal wall were unusually prominent. Both kidneys were too readily palpable and considered to be abnormally large for an infant of this size. The lower margin of the liver was situated $2 \mathrm{~cm}$. below the right costal margin. The perineum was clean and healthy in appearance.

Urine examined on the 19th day contained 770 WBC's /c.mm. In the centrifuged deposit there were 15 to 20 WBC's per high power field, occasional RBC's, moderately numerous bacteria, and an appreciable number of protozoa resembling Trichomonas vaginalis. Culture of the deposit yielded a dense mixed growth of a coliform bacillus, Staphylococcus aureus, and Staphylococcus albus.

Other investigations (on or about the 19th day) included those set out in Table I.

Further examinations of urine were carried out between the 19th and 63rd days of life on 10 occasions, and with one exception Trichomonas vaginalis and a significant number of pus cells were found to be present (Table II).

The mother's clinical notes contained no record of her having been infected with Trichomonas vaginalis. A 
TABLE I

Laboratory Findings at the Age of 19 Days

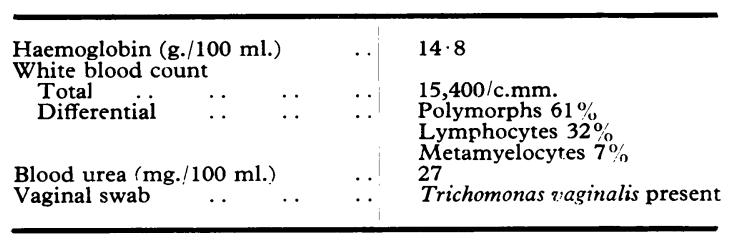

TABLE II

Results of Urine Examinations

\begin{tabular}{|c|c|c|c|}
\hline \multirow{2}{*}{$\begin{array}{c}\text { Age } \\
\text { (days) }\end{array}$} & \multirow{2}{*}{$\begin{array}{c}\text { Uncentri- } \\
\text { fuged } \\
\text { Urine } \\
\text { (WBC/c.mm.) }\end{array}$} & \multicolumn{2}{|c|}{ Centrifuged Deposit of Urine } \\
\hline & & $\begin{array}{c}\text { Trichomonas } \\
\text { vaginalis }\end{array}$ & Bacteria \\
\hline $\begin{array}{l}19 \\
21 \\
23\end{array}$ & $\begin{array}{c}770 \\
1,370 \\
45\end{array}$ & $\begin{array}{l}\text { Present } \\
\text { 3-5/h.p.f. } \\
\text { Present }\end{array}$ & $\begin{array}{l}\text { Fairly numerous } \\
\text { Numerous bacteria } \\
\text { Scanty; no growth } \\
\text { on culture }\end{array}$ \\
\hline $\begin{array}{l}29 \\
35 \\
41 \\
47 \\
55 \\
62\end{array}$ & $\begin{array}{l}4,200 \\
480 \\
250 \\
70 \\
<1 \\
80\end{array}$ & $\begin{array}{l}\text { Present } \\
\text { Present } \\
\text { Present } \\
\text { Present } \\
\text { Not found } \\
\text { Fairly }\end{array}$ & $\begin{array}{l}\text { Scanty } \\
\text { Numerous } \\
\text { Fairly numerous } \\
\text { Fairly numerous } \\
\text { Very scanty } \\
\text { Very scanty }\end{array}$ \\
\hline 63 & & $\begin{array}{l}\text { numerous } \\
\text { Present }\end{array}$ & Very scanty \\
\hline $\begin{array}{l}65 \\
66 \\
69 \\
70 \\
75\end{array}$ & $\begin{array}{l}\text { Occasional } \\
\text { Occasional } \\
\qquad \begin{array}{l}15 \\
<1 \\
<1\end{array}\end{array}$ & $\begin{array}{l}\text { Not found } \\
\text { Not found } \\
\text { Not found } \\
\text { Not found } \\
\text { Not found }\end{array}$ & $\begin{array}{l}\text { Very scanty } \\
\text { Scanty } \\
\text { Scanty } \\
\text { Very scanty } \\
\text { Scanty }\end{array}$ \\
\hline
\end{tabular}

vaginal swab of the mother taken following the discovery of trichomonal infection in the infant was negative.

Progress and treatment. Despite persistently abnormal urinary findings and the incidental development of purulent otorrhoea in the sixth week, the baby made uninterrupted general progress. The ear infection responded to erythromycin $(20 \mathrm{mg}$. given 6-hourly for 5 days). In view of the continued presence of Trichomonas vaginalis and pus in the urine, oral treatment with metronidazole (Flagyl), $50 \mathrm{mg}$., 8-hourly, was started on the 64th day. This was followed by a simultaneous rapid disappearance of the parasite and a fall in the number of white cells in the urine. Thereafter the white cells remained within normal limits according to the standards of Lincoln and Winberg (1964) (Fig. 1).

The baby's subsequent progress has been uneventful. At the age of 4 months urine examination was normal, as was intravenous pyelography.

\section{Discussion}

Trichomonas infection in the newborn is sufficiently rare to warrant comment. Schaffer (1960), Potter (1961), and Morison (1963) make no mention of genital or urinary trichomonal infection in the newborn.

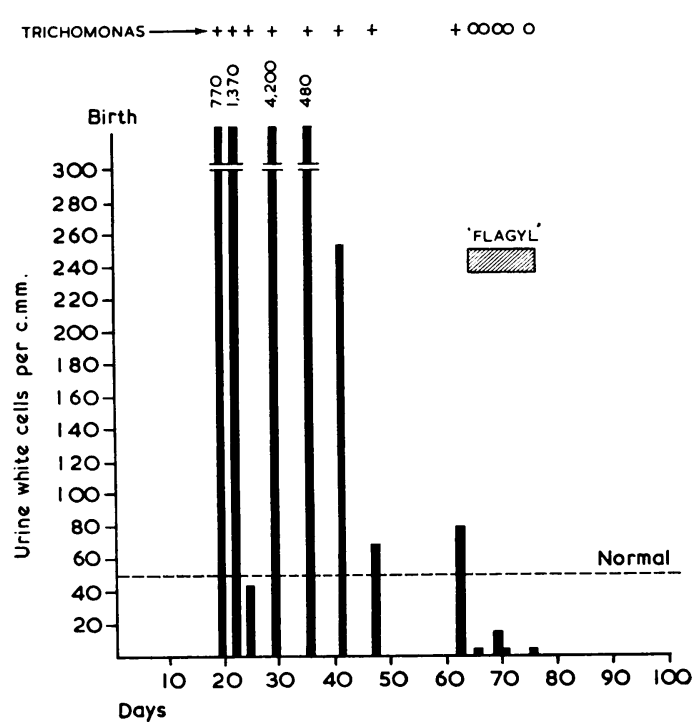

FIG.-Progress and treatment of the baby, showing the fall in the number of white cells in the urine.

Two well-documented cases have, however, been recorded in this country by Crowther (1962). Both infants were of low birthweight, and in one there was a congenital abnormality of the urinary tract associated with meningomyelocele. Only one of the mothers concerned was found to be harbouring Trichomonas vaginalis during the postnatal period.

In a recent Polish investigation (Komorowska, Kurnatowska, and Liniecka, 1962) 6 of 35 female infants $(17 \cdot 2 \%)$ with vaginal discharge, aged less than 3 weeks, were found to be harbouring the parasite. The methods of investigation differed from ours in that the diagnosis was based on culture of the protozoa. Although Komorowska et al.'s findings were correlated with low standards of hygiene and sanitation, no mention was made of any specific examination of the mothers for Trichomonas vaginalis.

In later childhood trichomonal vaginitis is probably somewhat more common. Lang (1959) investigated 110 cases of vaginitis in girls who had not yet started menstruating, and found Trichomonas vaginalis in only 4 . Nelson (1964) in his textbook mentions trichomonas as a rare cause of vaginitis before puberty.

Trichomonas vaginalis as a cause of urinary tract infection is not common but findings in so far as adult patients are concerned are well documented. The presence of trichomonas in non-catheter specimens of urine is due in most cases to contamin- 
ation by vaginal secretion. One of us (H.G.K.), however, has on a few occasions found Trichomonas vaginalis in catheter specimens of urine from female patients and the results were confirmed by reexamination. Infection of both upper and lower urinary tract due to this organism is mentioned by Campbell (1954) and by Lewis and Carroll (1928). Manwell's (1934) observations suggest that urinary symptoms can occur in the presence of trichomonal vaginitis without the protozoa being found in the urine. In a series of 19 patients with trichomonal vaginitis submitted to full urological investigation the parasite was demonstrated in the urine of only 3 .

No mention of urinary tract infection by Trichomonas vaginalis in children is made by Meredith Campbell in his Clinical Pediatric Urology (1951), or by Williams in his Urology in Childhood (1958). Nor have we been able to find any recorded case of clinically manifest urinary tract infection due to Trichomonas vaginalis in the newborn period. Urinary tract infection secondary to Trichomonas vaginalis, therefore, appears to be very rare in infancy and childhood.

With regard to our patient we feel justified in ascribing the urinary signs, i.e. persistent pyuria and moderate, apparently temporary, renal enlargement to the trichomonal infection and not to bacterial infection. In our experience the presence of a moderate number of bacteria in the centrifuged deposit of a non-catheter urine in this age-group does not indicate significant bacterial urinary infection. Our observations (unpublished), using quantitative bacterial cultures in the newborn, strongly support this view. There is support for this view in the rapidity with which anti-trichomonal treatment was followed by the elimination of protozoa from both urine and vagina, and by the disappearance of pyuria. Despite the presence of trichomonads in the vagina of our patient, clinical signs of vaginitis were absent.

The source and mode of infection in the infant remain obscure. It is possible that the rarity of trichomonal infection among newborn infants in this country is explained by eradication of infection in the mother at the time of antenatal care. This explanation may, however, require reconsideration.

Despite negative maternal findings, we are inclined to believe that the mother was the source of infection. She may have had an asymptomatic infection, though this is less common in females than in males. Pregnant women without symptoms of vaginal infection are not normally examined for Trichomonas vaginalis. Examination for this specific purpose was carried out on the mother on only one occasion several weeks after delivery. Although the findings were negative it is recognized that in non-pregnant women it is not uncommon for the presence of Trichomonas vaginalis to be missed on a single microscopical examination.

The treatment of Trichomonas vaginalis infection has been greatly improved by the introduction in 1960 of metronidazole. Experience has shown that the drug is highly effective in eradicating the parasite from both vaginal secretions and urine. Crowther (1962) successfully treated his two cases of Trichomonas vaginalis infection by giving $50 \mathrm{mg}$. metronidazole 3 times daily for 7 days, using the oral route. Our experience confirms the effectiveness of this dosage and régime. No undesirable side-effects were observed during or after the period of treatment.

\section{Summary}

A female infant of approximately 28 weeks' gestation was noted to have abdominal distension and readily palpable kidneys on the 19th day of life. Trichomonas vaginalis was present in the urine and was associated with significant pyuria. These findings persisted until the 64th day when oral treatment with metronidazole $50 \mathrm{mg}$. t.d.s. for 7 days was started, and proved rapidly effective in eradicating the parasite and the pyuria. The infant was normal at a follow-up examination at 4 months.

We are indebted to Miss M. Patullo for her customary conscientious co-operation, and gratefully acknowledge the reliable and enthusiastic help of Mr. Brian King, who performed most of the urine examinations.

\section{REFERENCES}

Campbell, M. (1951). Clinical Pediatric Urology. W. B. Saunders, Philadelphia and London.

- (1954). Urology, Vol. 1, p. 586. W. B. Saunders, Philadelphia and London.

Crowther, I. A. (1962). Trichomonas vaginitis in infancy. Lancet, $1,1074$.

Komorowska, A., Kurnatowska, A., and Liniecka, J. (1962). Occurrence of Trichomonas vaginalis (Donné) in girls in relation to hygienic conditions. [In Polish.] Wiad. Parazyt., 8, 247.

Lang, W. R. (1959). Premenarchal vaginitis. Obstet. Gynec., 13, 723.

Lewis, B., and Carroll, G. (1928). Case of trichomonas vaginalis: infection of kidney pelves. F. Urol. (Baltimore), 19, 337.

Lincoln, K., and Winberg, J. (1964). Studies of urinary tract infections in infancy and childhood. III. Quantitative estimation of cellular excretion in unselected neonates. Acta paediat. (Uppsala), 53, 447.

Manwell, E. J. (1934). Urinary symptoms in relation to Trichomonas vaginalis infestation. New Engl. F. Med., 211, 567.

Morison, J. E. (1963). Foetal and Neonatal Pathology, 2nd ed. Butterworths, London.

Nelson, W. E. (1964). Text Book of Pediatrics, 8th ed. W. B. Saunders, Philadelphia and London.

Potter, Edith L. (1961). Pathology of the Fetus and Infant, 2nd ed. Year Book Publishers, Chicago.

Schaffer, A. J. (1960). Diseases of the Newborn. W. B. Saunders, Philadelphia and London.

Williams, D. I. (1958). Urology in Childhood. Vol. XV of Encyclopaedia of Urology, ed. C. E. Alken, V. W. Dix, H. M. Weyrauch, and E. Wildbolz. Springer, Berlin. 